\title{
ERITROPOYETINA: MÁS ALLÁ DE LA PROLIFERACIÓN Y MADURACIÓN ERITROIDE
}

\author{
Oscar Andrés Peñuela B. MD, M.Sc. ${ }^{1 *}$ y Lina Andrea Gómez R. Bact. Ph. D. ${ }^{2}$ \\ ${ }^{1}$ Profesor del departamento de Fisiología, Facultad de Medicina, Universidad Militar Nueva Granada, Bogotá D.C. ${ }^{2}$ \\ Coordinadora del Banco de Tejidos y Células, Hemocentro Distrital. Secretaría Distrital de Salud de Bogotá D.C.
}

\begin{abstract}
Resumen
El sistema hematopoyético de los vertebrados requiere de mecanismos que aseguren una continua producción de nuevas células necesarias para reemplazar los elementos maduros de la sangre que tienen una vida limitada. Esta continua producción es realizada por las células madre pluripotenciales, a través de progenitores multipotenciales, una de las cuales es la línea eritroide. La eritropoyetina (EPO), es el factor clave de este proceso al asegurar, como tradicionalmente se ha sabido, la proliferación y diferenciación del componente inmaduro. De otra parte, una creciente evidencia demuestra que la EPO no solamente está relacionada con el mantenimiento de los precursores eritroides, sino también con la viabilidad de los eritrocitos maduros circulantes. Así mismo, se conocen cada vez más funciones no eritropoyéticas de esta fascinante citoquina, abriendo el panorama terapéutico a muchos pacientes que padecen cáncer o sufren las consecuencias de la isquemia tisular. Este artículo es una revisión general de la biología de la EPO, de sus efectos fisiológicos sobre diferentes tejidos y su relación con los fenómenos de muerte celular programada de los eritrocitos maduros.
\end{abstract}

Palabras clave: eritropoyetina, eritropoyesis, apoptosis

\section{ERYTHROPOIETIN: BEYOND ITS ROLE IN ERYTHROID LINEAGE}

\begin{abstract}
Vertebrate hematopoietic system requires some mechanisms that granted constitutive renewal of older blood cells. This task is done by pluripotent and multipotent stem cells, among them the erythroid lineage. These cells have two remarkable qualities: first, they can be grown indefinitely and maintain a normal karyotype and second, they can be induced to differentiate into specific cell lines, e.g. erythroblast and erythrocytes. Erythropoietin (EPO) is the key factor of this process. This cytokine allows differentiation and proliferation of immature erythroid component. There is increasing evidence reporting that EPO also helps to maintain viability of circulating mature red blood cells. In addition, many non-erythroid functions for this cytokine are being documented, offering patients new therapeutic alternatives to tissular ischemia. We have reviewed some critical aspects of EPO biology, physiology, and its relationship with mature erythrocyte apoptosis.
\end{abstract}

Keywords: erythropoietin, erythropoiesis, apoptosis

* Correspondencia: Oscar Peñuela Briceño oscar.penuela@unimilitar.edu.co. Dirección postal: Laboratorio de fisiología, Facultad de Medicina, Universidad Militar Nueva Granada, Tr. 3a \#49-00, Bogotá, Colombia. Teléfono: 6409420 Ext. 133.

Recibido: Febrero 8 de 2010 Aceptado: Junio 15 de 2010. 


\title{
ERITROPOÉTINA: ALÉM DA PROLIFERAÇÃO E DA MADURAÇÃO ERITROIDE
}

\begin{abstract}
Resumo
O sistema hematopoiético dos vertebrados precisa de mecanismos que assegurem uma continua produção de novas células necessárias para substituir os elementos maduros do sangue que possuem uma vida limitada. Esta produção contínua é realizada por células-tronco pluri-potenciais, a través de progenitores multi-potenciaes uma das quais é a linhagem eritróide. A eritropoetina (EPO) é o fator-chave deste processo já que assegura, como é tradicionalmente conhecido, a proliferação $e$ diferenciação do componente imaturo. Além disso, uma crescente evidencia demonstra que a EPO não só esta relacionada com a manutenção dos precursores eritroides, também com a viabilidade dos eritrócitos maduros circulantes. Mesmo assim, se conhecem cada vez mais funções não eritropoeticas desta fascinante citoquina, abrindo o panorama terapêutico a muitos pacientes com câncer o que sofrem as conseqüências da isquemia tissular. Apresenta-se una revisão geral da biologia da EPO, e de seus efeitos fisiológicos sobre os diferentes tecidos e sua relação com os fenômenos de morte celular programada dos eritrocitos maduros.
\end{abstract}

Palavras-chave: eritropoetina; eritropoesis; apoptose

\section{Introducción}

Está demostrado que la EPO es la principal citoquina relacionada con el control de la eritropoyesis. Paul Bert y su colaborador, Denis Jourdanet, demostraron que los efectos fisiológicos de los gases dependían de su presión parcial estableciendo la relación entre hipoxia tisular y la producción de eritrocitos (1). Carnot y Deflandre postularon que existía un factor humoral, que denominaron "hemopoyetina", que regulaba la producción de glóbulos rojos; experimentalmente demostraron que cuando removían el plasma de conejos que habían sido sangrados y eran anémicos y lo transfundían a los conejos control, éstos desarrollaban reticulocitosis (2). La eritropoyesis está regulada por varias citoquinas incluyendo, el factor estimulante de colonias del granulocitos (G-GSF), el factor de células madre (SCF), las interleuquinas (IL) 1, 3, 4, 6, 9, 11, el factor estimulante de colonias de granulocítos y macrófatos (GM-CSF), el factor de crecimiento insulínico y la EPO. La EPO actúa en los estadios tardíos de desarrollo de los progenitores eritroides, principalmente sobre las unidades formadores de colonias eritroides (UFC-E) $(3,10,11)$.

En 1950 se documentó la relación entre el estímulo hipóxico y la inducción de reticulocitosis, el incremento de la hemoglobina y la producción de hiperplasia medular (3) y posteriormente se estableció que el sitio principal de producción de EPO son las células intersticiales peritubulares del riñón en el adulto y que el hígado es un órgano eritropoyético secundario que la produce en el feto (4). En 1985 se reportó la purificación bioquímica de EPO humana y se hizo la clonación del gen y años más tarde se obtuvo la proteína de forma recombinante $(5,6)$. A partir de ese momento se han desarrollado varias moléculas de EPO que cumplen con mayor eficacia la labor eritropoyética, en virtud de su mayor contenido de residuos de carbohidratos (hiperglicosilación), lo que les otorga una vida media más prolongada al retardar la depuración hepática (7).

\section{Características biológicas de la EPO}

El gen de la EPO humana está localizado en el cromosoma 7 (7q 21-22), presenta cinco exones y cuatro intrones y codifica una proteína de 193 aminoácidos. Es una glicoproteína de $34 \mathrm{kDa}$ y posee un alto contenido en carbohidratos (39\%) distribuidos en cuatro grupos: tres $\mathrm{N}$-glicosilaciones en los residuos de asparagina en las posiciones 24, 38 y 83 y, una O-glicosilación en el residuo de serina en la posición 126 . Algunos de estos carbohidratos terminan en grupos de ácido siálico, que permite la unión de la EPO a los receptores específicos de superficie de los precursores eritroides estimulando 
su diferenciación y maduración clonal. La presencia del ácido siálico sobre los grupos carbohidrato retarda la depuración hepática de EPO y garantiza una estimulación más prolongada de los receptores eritroides (figura 1) (8).

Otra característica importante de la estructura de la EPO son los dos enlaces disulfuro, uno que se forma entre las cisteínas localizadas en las posiciones 7 y 161, y el otro entre las cisteínas de las posiciones 29 y 33. Su estructura terciaria está definida por cuatro hélices alfa antiparalelas con asas adjuntas, logrando así mantener la conformación correcta que le permite unirse a su receptor; si la pierde, su actividad biológica es abolida (9).

El papel crucial de la EPO y de su receptor (EPOr) está soportado por los estudios en ratones knockout: los ratones $\mathrm{EPO}^{-/}$y $\mathrm{EPOr}^{-/}$mueren al día 12,5 de vida embrionaria como consecuencia de la anemia severa que desarrollan. Estos modelos animales exhiben un número normal de progenitores eritroides (UFB-E y UFC-E: unidad formadora de colonias eritroide) a nivel del hígado fetal, lo cual demuestra que, ni la EPO ni su receptor, son necesarios para el compromiso inicial de las células madre con la progenie eritroide (10).

\section{El receptor de EPO}

El EPOr es expresado como una proteína de 66 a 78 $\mathrm{kDa}$ conformada por tres dominios: uno extracelular, uno transmembranal y uno intracelular. Cuando una molécula de EPO se une a dos receptores localizados sobre la superficie de la célula, se induce la fosforilación de las tirosinas del dominio intracelular, iniciándose así la cascada de señalización intracelular que regula la expresión génica que controla la sobrevida, proliferación y diferenciación de los precursores eritroides.

La EPO no solamente actúa sobre este tipo de células, sino que su actividad se ve reflejada en múltiples tejidos, como el nervioso, que es capaz de sintetizar EPO para su desarrollo, funcionamiento y protección en la isquemia (11-12), y los pacientes anémicos tratados con EPO experimentan una mejoría importante en su función cognitiva (13). Sin embargo, el receptor que media los efectos neuroprotectores de la EPO difiere del receptor hematopoyético en afinidad, peso molecular y proteínas asociadas. De esta forma, algunas modificaciones en la estructura de la EPO, como la carbamilación de las lisinas, anulan su actividad eritropoyética pero se mantiene su efecto de protección tisular (14).

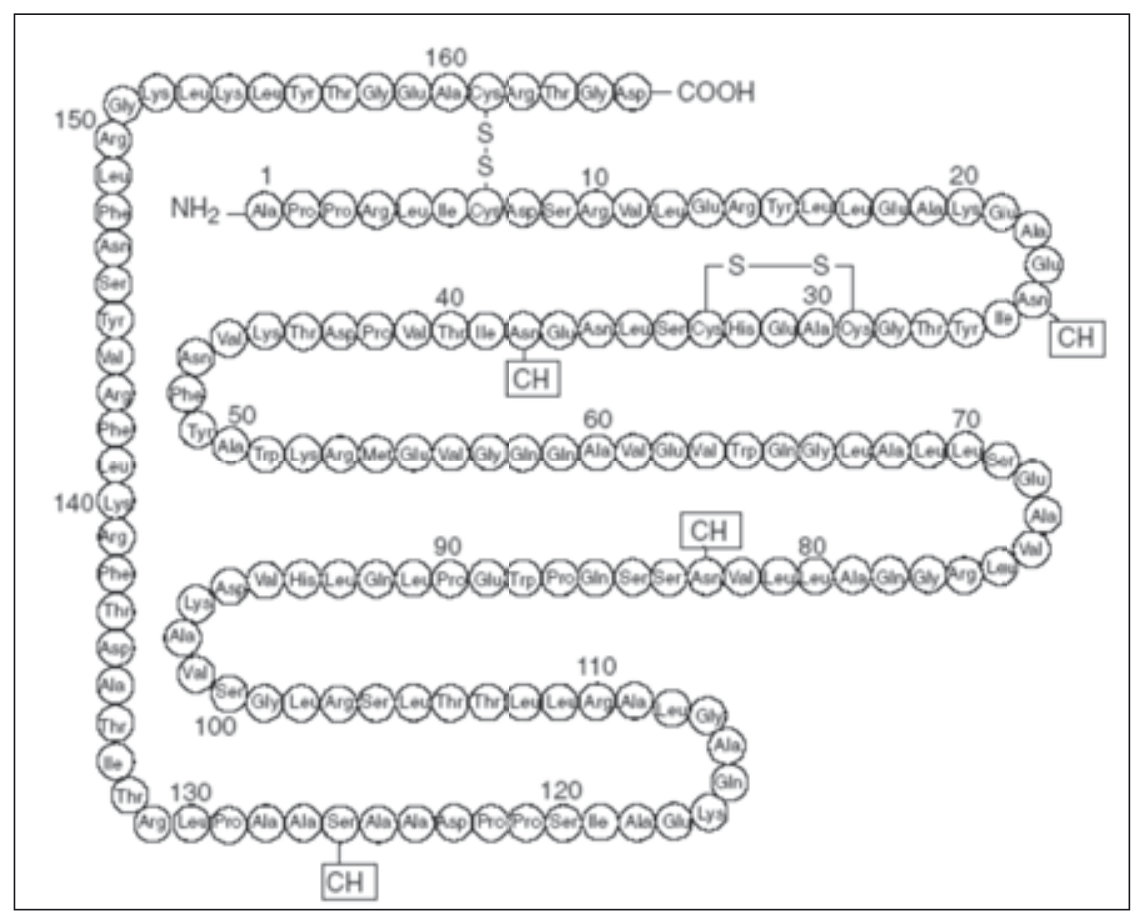

FIGURA 1. Estructura primaria de la eritropoyetina. 
EPO y EPOr no sólo se expresan en hígado y en riñón sino también en macrófagos de la médula ósea, neuronas, astrocitos, células endoteliales neuronales, microglía y oligodendrocitos y células del trofoblasto; también la EPO se puede encontrar en la leche materna y en algunos tumores malignos. El EPOr se puede expresar en células no hematopoyéticas tales como células endoteliales. El tratamiento con EPO mejora la función sexual en pacientes con insuficiencia renal terminal, al estimular la producción de testosterona y actuar directamente sobre las células de Leydig (Tabla 1) $(15,16)$.

Debido a que se ha encontrado que la EPO puede ser producida por el SNC y por los órganos reproductores femeninos, se ha buscado ver cual es su función y cómo es la regulación de la producción en estos sitios, que es diferente a la del riñón. En el cerebro es neuroprotector, en el útero es estrógeno inducible e induce angiogénesis.

TABLA 1. Expresión de EPOr y funciones potenciales en células normales no eritroides.

\begin{tabular}{lc}
\hline Expresión de EPOr & Función \\
\hline Astrocitos & Disminución de apoptosis \\
Cardiomiocitos & Mitogénesis \\
Células endoteliales & Mitogénesis \\
Megacariocitos & Síntesis y liberación de Endotelina 1 \\
Células mesangiales (proliferación y maduración) & Maduración \\
Células mieloides & Incrementa proliferación in vitro \\
& Proliferación multilinaje \\
Inmunomodulación
\end{tabular}

\section{Acción de la EPO}

La EPO es producida inicialmente en el feto por el hígado y en el adulto por el riñón, su principal función es estimular la producción de eritrocitos y la concentración de oxígeno en los tejidos es la que regula su producción. La hipoxia induce la activación transcripcional de los genes de EPO y el incremento de ésta induce la producción de eritrocitos. La EPO en el organismo actúa de tres formas bien definidas: autocrina, endocrina y paracrina. La acción endocrina se inicia en el riñón, donde la hipoxia da lugar a un incremento en la expresión de EPO por la acción del factor 1 inducible por hipoxia (HIF-1); la actividad paracrina se evidencia en las neuronas cerebrales, donde las células que producen EPO están en estrecha vecindad con las células receptoras y finalmente, algunas células cerebrales, en determinadas condiciones como la isquemia tisular, producen su propia EPO, lo cual refleja su acción autocrina (15).

La interacción de la EPO con su receptor homodimérico (figura 2) determina un cambio conformacional en las unidades del EPOr, con la consecuente activación de la maquinaria de transducción de señales intracelulares. Estas vías son muy complejas y han sido caracterizadas parcialmente. La EPO se une a los receptores de superficie de los precursores eritroides en la médula ósea para regular su proliferación, maduración y sobrevida. Aparentemente estos receptores son expresados principalmente en las UFC-E y en los pronormoblastos. Los EPOr localizados sobre la superficie de las UFB-E son muy escasos, lo cual explicaría la poca sensibilidad de estas células a la EPO (17).

Los estudios cristalográficos indican que el EPOr existe como un dímero preformado. Así, una molécula de EPO activa al receptor induciendo su dimerización y el cambio conformacional que es necesario para la activación, mediada por la transfosforilación de la proteína Janus tirosina quinasa 2 (JAK2), que se encuentra unida al receptor en el dominio transmembranal. La JAK2 fosforila ocho residuos tirosina en el dominio citoplasmático del EPOr, los cuales sirven como sitios de acople para varias proteínas de señalización intracelular que contienen dominios $\mathrm{SH} 2$. Estas proteínas son a su vez fosforiladas y activadas en sus residuos tirosina. Una de estas proteínas es el transductor de señal y activador de la transcripción o STAT5, que se disocia del EPOr y se transloca al núcleo para activar numerosos genes blanco, tales como el Bcl- $\mathrm{x}_{\mathrm{L}}$, que es un inhibidor de la apoptosis. La expresión de la proteína STAT5 declina rápidamente en los estadios finales de maduración eritroide (eritroblasto policromatófilo y ortocromático).

La inhibición de la apoptosis por la vía EPOr activadoJAK2, es fundamental para la diferenciación eritroide. 


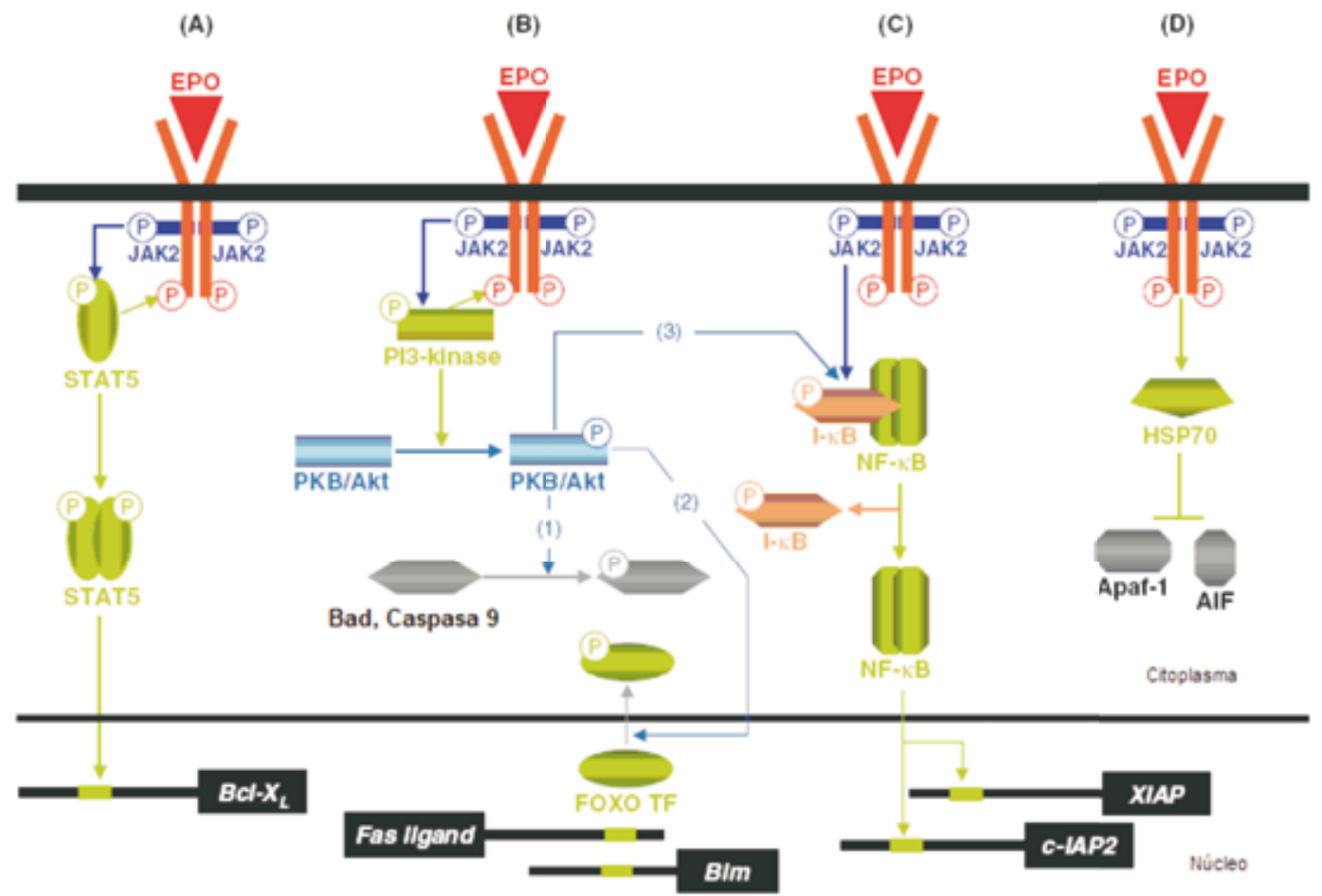

FIGURA 2. Representación esquemática de las vías de unión de la EPO a su receptor e inhibición de la apoptosis.

La deficiencia de JAK2 causa muerte embrionaria debido a la ausencia de eritropoyesis definitiva. Los ratones deficientes en STAT5a/5b presentan anemia que se correlaciona con una expresión disminuida de $\mathrm{Bcl}-\mathrm{x}_{\mathrm{L}}$ y un incremento de la apoptosis en eritroblastos tempranos (18). Sin embargo, la EPO induce la activación de otros elementos que incluyen por ejemplo, la proteína Shc y la fosfolipasa C- $\gamma 1$ (inducen la proliferación celular) y la fosfatidilinositol quinasa 3 (PI3K) que promueve la sobrevida eritroide. De esta manera, por medio de la activación de JAK2, el EPOr induce múltiples vías de señalización, todas orquestadas en prevenir la apoptosis e inducir la proliferación y diferenciación terminal de los progenitores eritroides.

Así mismo, la EPO induce la expresión del factor transcripcional GATA-1, un factor fundamental en el control de la diferenciación eritropoyética; los niveles más altos de GATA-1 son los encontrados en las UFC-E y en los proeritroblastos. Los estudios en células madre GATA-1 1 muestran que estas células no maduran más allá del estadio de proeritroblasto y entran en una rápida apoptosis, lo que sugiere un papel activo de GATA-1 en la sobrevida y la maduración eritroide (19). De igual forma se cree que los genes blanco de GATA-1 son estrictamente necesarios para la proliferación y diferenciación celular. Uno de estos genes es el $B c l-x_{L}$, una proteína antiapoptótica cuya expresión es fuertemente inducida por GATA-1.

El factor Bcl- $x_{L}$ pertenece a la familia de proteínas $\mathrm{Bcl}-2$, que actúan como importantes reguladores de la muerte celular, integrando señales tanto proapoptóticas como antiapoptóticas. Bcl- $x_{L}$ pertenece al grupo de proteínas antiapoptóticas que inhiben a otros factores de la misma familia, que generan señales para la muerte celular (20). Estudios en modelos animales de células madre $\mathrm{Bcl}-\mathrm{x}_{\mathrm{L}}{ }^{-1}$ demostraron que estas células eran incapaces de generar células eritroides definitivas; los ratones knock-out $\mathrm{Bcl}-\mathrm{x}_{\mathrm{L}}^{-/}$mueren durante la embriogénesis, observando una extensa apoptosis de las células hematopoyéticas inmaduras. Así mismo, en los modelos de eritropoyesis adulta, los animales $\mathrm{Bcl}-\mathrm{x}_{\mathrm{L}}{ }^{-1}$ desarrollaron un cuadro de anemia hemolítica severa, reticulocitosis y trombocitopenia y los análisis de médula ósea mostraron hiperplasia de las líneas eritroide y megacariocítica. Además se observó que los 
animales $\mathrm{Bcl}-\mathrm{x}_{\mathrm{L}}^{-/}$tienen una deficiencia en la síntesis del grupo hem y por tanto de la hemoglobina (21-23).

Finalmente, se ha demostrado que la regulación del calcio intracelular por la EPO es otro de los mecanismos de señalización que controlan la proliferación y diferenciación de las células eritroides, a través de canales de calcio independientes de voltaje. La EPO estimula la entrada de calcio a la célula, no solamente en ciertos progenitores eritroides como las UFB-E, sino también en células no eritroides, como los mioblastos, expandiendo la población de progenitores durante su diferenciación. También incrementa la viabilidad celular en neuronas carentes de factor de crecimiento neuronal, incrementando la captación y la concentración intracelular de calcio, sugiriendo que la EPO estimula la función neuronal a través de la activación de estos canales (24).

\section{EPO recombinante humana (rHuEPO)}

El desarrollo de las técnicas de ADN recombinante permitió la producción de rHuEPO. Antes de la disponibilidad de rHuEPO, el único tratamiento disponible para los pacientes con anemia severa era la transfusión de glóbulos rojos. Desafortunadamente, la transfusión de sangre implica reacciones adversas que incluyen entre otras, el riesgo de transmisión de enfermedades infecciosas, la sobrecarga de hierro por múltiples transfusiones y los efectos indeseables sobre el sistema inmunológico.

Así, la rHuEPO se convirtió en un candidato terapéutico importante en el tratamiento de los pacientes anémicos, de hecho es el tratamiento actualmente recomendado en muchas categorías de anemia (25). Sin embargo, se ha observado que aproximadamente el $50 \%$ de los pacientes responden escasamente a la administración de $\mathrm{rHuEPO}$, y producen anticuerpos específicos contra la molécula (26). Actualmente se sigue trabajando en el desarrollo de nuevas modificaciones a la molécula de EPO clonada inicialmente, para mejorar su eficacia y seguridad.

El tratamiento con rHuEPO de los pacientes anémicos con cáncer que reciben terapia citotóxica, induce a un incremento significativo en los niveles de hemoglobina y a una reducción en la utilización de las transfusiones de sangre, efectos asociados a una mejoría en la calidad de vida de estos pacientes (27).
Uno de los principales efectos adversos del tratamiento con EPO en pacientes con anemia e insuficiencia renal crónica es el incremento de la presión arterial media; esto se ha atribuido al efecto de la EPO sobre las células endoteliales, al incrementar su proliferación, migración y protección frente a la apoptosis. Además, aumenta la concentración intracelular de calcio, lo cual produce una regulación positiva de los receptores del factor de crecimiento endotelial y aumenta la producción de endotelina 1.

La EPO es importante para la angiogénesis en diferentes situaciones como el embarazo, la menstruación y el entrenamiento en la altura, donde mejora la oxigenación tisular (15). Algunos tumores sólidos expresan EPOr y teóricamente se sospecha que la capacidad de la EPO para estimular la angiogénesis podría incrementar la perfusión de tumores y soportar su crecimiento. Sin embargo, varios estudios han demostrado la seguridad y el beneficio de la utilización de rHuEPO en pacientes oncológicos y no han evidenciado un impacto significativo de efectos adversos (28).

Poco se conoce acerca de la evolución de la eritropoyesis después de la interrupción de la terapia con EPO. En un trabajo experimental en un modelo murino (con sobrecarga de hierro), se demostró que aproximadamente tres semanas después de la detención del tratamiento se presentaba una severa disminución en el número de reticulocitos, del receptor soluble de transferrina, de la celularidad eritroide, de la incorporación de hierro en hem y del número de colonias eritroides. Después de ocho semanas se observó una recuperación lenta y parcial y no se encontraron anticuerpos ni otros factores endógenos inhibitorios (29). En un estudio clínico controlado realizado por Polenakovic y col (30) se vio que la sobrevida de los glóbulos rojos, medida por la técnica del $51 \mathrm{Cr}$, aumentó durante la terapia prolongada con $\mathrm{rHuEPO}$ y después de la finalización de la terapia, la sobrevida eritrocitaria regresó a los valores previos al tratamiento.

\section{Células eritroides y apoptosis}

Los eritrocitos maduros humanos son células completamente diferenciadas, carecen de núcleo, mitocondrias y demás organelas citoplasmáticas y tienen una vida promedio en el adulto de 120 días, al cabo de la cual los procesos de senescencia conducen a su depuración de la sangre periférica por parte del sistema retículo endotelial. El envejecimiento eritrocitario está asociado 
con disminución del tamaño celular, microvesiculación de la membrana plasmática, cambios progresivos en la forma eritrocitaria (discocito a esferoequinocito), alteraciones del citoesqueleto relacionadas con la degradación de espectrina y pérdida de la asimetría de los fosfolípidos de la membrana con externalización de fosfatidilserina, representando estos cambios señales para los macrófagos que los fagocitan (34).

A pesar de las similitud entre los cambios mencionados y algunas de las características de las células en proceso de apoptosis, los eritrocitos maduros eran considerados como las únicas células mamíferas que carecían de la maquinara celular para los procesos de muerte celular programada. Sin embargo, se demostró que los eritrocitos maduros están regulados por un proceso de autodestrucción que funciona en ausencia de núcleo y de mitocondrias y que parece estar acelerado por un incremento del calcio intracelular. Los eritrocitos expresan constitutivamente la "maquinaria de muerte" capaz de inducir todos los cambios celulares propios de la apoptosis. Además, los inhibidores de las cisteín proteasas inhiben este proceso de muerte celular permitiendo la sobrevida de los eritrocitos in vivo e in vitro. Se ha sugerido además que existen en la circulación factores producidos por otras células, que previenen o retrasan la muerte eritrocitaria inducida por calcio (35).

Se ha demostrado que los eritrocitos maduros contienen cantidades importantes de caspasa 3 y caspasa 8 , pero carecen de otros componentes apoptóticos como caspasa 9, Apaf-1 y citocromo C. Sin embargo, en este estudio no se pudo evidenciar la actividad de estas caspasas, pero sí la de la calpaína, una proteasa dependiente de calcio (36). Existe amplia evidencia acerca del papel de la homeostasis del calcio en los glóbulos rojos y su relación con las alteraciones morfológicas y la senescencia eritrocitaria. La unión de calcio a la calpaína heterodimérica induce la disociación de la estructura de la enzima en sus subunidades constituyentes, cada una con cuatro sitios de unión a calcio. En la forma monomérica, la subunidad catalítica tiene dos veces la afinidad por el calcio de la calpaína nativa, mientras que tras la conversión autoproteolítica, ésta se incrementa 20 veces. La activación de la calpaína tiene lugar en condiciones fisiológicas (37).

Se ha observado que el tratamiento de los glóbulos rojos con un ionóforo de calcio induce a la aparición de las características propias de una célula apoptótica nucleada. El choque osmótico, el estrés oxidativo, la remoción del cloro extracelular y la depleción energética, conducen a la activación de canales catiónicos permeables al calcio lo cual acelera la muerte celular y su depuración por parte del sistema retículo endotelial (31). La adición de eritropoyetina beta a glóbulos rojos maduros inhibe la activación de los canales de calcio y restringe la aparición de algunas características (dependientes de un aumento del calcio intracelular) propias de células en proceso de apoptosis, tales como la externalización de fosfatidilserina (32). También se ha demostrado que el incremento en la concentración intracelular de calcio activa los canales de potasio sensibles a calcio (canales Gardos) hiperpolarizando la célula y facilitando la salida de cloro; con la pérdida de $\mathrm{KCl}$ y del agua osmótica obligada se induce el encogimiento celular. La inhibición de los canales Gardos impide la disminución del tamaño celular y además restringe la externalización de fosfatidilserina (33).

En conclusión, la presencia de caspasas no prueba necesariamente que la muerte celular sea absolutamente dependiente de éstas; sin embargo, la pérdida del fenotipo de una caspasa específica o de su regulador no elimina la posibilidad de compensación por otra. Así mismo, la actividad de caspasas no significa siempre muerte y no impide la actividad de otros mecanismos letales. La activación de estas proteínas parece ser la principal vía para la inducción de la apoptosis, pero cuando estas no están presentes o hay una falla en este mecanismo, la célula cuenta con otras vías alternas las cuales activa para inducir la apoptosis (38). Al eritrocito maduro se le ha designado el nombre de "momias circulantes" derivadas de un proceso de especialización celular en el cual, los precursores eritroides destruyen y eliminan sus organelas en un proceso dependiente de la actividad de ciertas proteasas y que se inició en la médula ósea. En los glóbulos rojos humanos el proceso apoptótico se activa a los 120 días en promedio (39).

Los transportadores de lípidos de la membrana en general son llamados "flipasas", muestran una actividad disminuida como consecuencia del estrés oxidativo durante envejecimiento eritrocitario y por la acción de la caspasa 3 (40-42). La proteína integral de membrana más abundante en el eritrocito es la banda 3 que es intercambiador aniónico y tiene un papel crucial en la estructura celular, al interconectar la bicapa con el citoesqueleto de espectrina. Se ha demostrado que la caspasa 3, al ser activada por el estrés oxidativo, cliva al dominio $\mathrm{N}$ terminal citoplasmático de la proteína banda 3 , ayudando a su degradación y alterando la 
estructura y el funcionamiento del eritrocito. Se plantea además que la caspasa 3 interviene en el envejecimiento eritrocitario, ya que se detecta en concentraciones importantes en los eritrocitos envejecidos pero no en los jóvenes (44).

\section{Neocitólisis}

Tradicionalmente se ha considerado que el control de la masa eritrocitaria corporal está determinado únicamente por la producción renal de la EPO, que ejerce su acción como factor de crecimiento específicamente sobre los precursores eritroides tempranos. Además, se asume que los eritrocitos que alcanzan una edad máxima en la circulación son retirados de manera específica por las células del sistema retículoendotelial. Sin embargo, se ha comenzado a dilucidar un mecanismo fisiológico que reduce la sobrevida de los eritrocitos circulantes a través de un proceso denominado neocitólisis, que implica la destrucción rápida de las células rojas jóvenes circulantes, y funciona al parecer como un mecanismo inmediato adaptativo en dos situaciones especiales: en la exposición a bajas tensiones de oxígeno (altura) y en los vuelos espaciales (45).

Los astronautas por ejemplo, experimentan una disminución aproximadamente de $10 \%$ a $15 \%$ en la masa total eritrocitaria a la primera semana de microgravedad, como consecuencia de la disminución en la secreción renal de la EPO (46). Teniendo en cuenta que dos semanas antes del despegue la sobrevida de los glóbulos rojos marcados con ${ }^{51} \mathrm{Cr}$ es normal, es posible pensar que son los eritrocitos más jóvenes (de menos de dos semanas) los que sufren un proceso selectivo de lisis celular (47). Al igual que los astronautas, las personas residentes en sitios con baja tensión de oxígeno (altura), experimentan un proceso acelerado de "eritrólisis", disparado por la disminución en la concentración de la EPO cuando descienden al nivel del mar.

En los dos casos anteriores, el incremento en los niveles de ferritina sérica, que refleja los depósitos corporales de hierro, se correlaciona directamente con la destrucción eritrocitaria. El porcentaje de reticulocitos permanece constante hasta la segunda semana, y luego empieza a disminuir. Esto refleja que la disminución de $\mathrm{EPO}$, que desencadena la apoptosis de los precursores eritroides, es un evento más tardío. Adicionalmente, el proceso hemolítico se evita con la administración subcutánea de pequeñas dosis repetidas de rHuEPO, que mantiene constante la concentración sérica de EPO y evita el nadir que conduce a la neocitólisis. Esto es especialmente importante en el entendimiento de la fisiopatología y la terapéutica de la anemia de la enfermedad renal crónica (48).

Las circunstancias antes mencionadas han llevado a postular a la neocitólisis como un mecanismo rápido y limitado de destrucción selectiva de glóbulos rojos, que proporciona un medio eficaz de adaptación inicial en circunstancias de eritrocitosis

TABLA 2. Acciones no eritropoyéticas de la rHuEPO y su utilidad en medicina

\begin{tabular}{llc}
\hline \multicolumn{1}{c}{ Modelo experimental } & \multicolumn{1}{c}{ Utilidad clínica potencial } & Referencia \\
\hline Murino & $\begin{array}{l}\text { Reducción del estrés oxidativo en retinopatía diabética } \\
\text { Protección frente al daño isquémico en eventos cerebrovas- } \\
\text { culares }\end{array}$ & 51 \\
Humano & $\begin{array}{l}\text { Protección frente al daño isquémico en cirugía de colon } \\
\text { Murino }\end{array}$ & 53 \\
Mumanojo de la esquizofrenia & $\begin{array}{l}\text { Protección al cardiomiocito después de infarto agudo de } \\
\text { miocardio }\end{array}$ & 54 \\
Murino & Mejor patrón de neurodesarrollo en neonatos prematuros & 56 \\
Humano & Mejor pronóstico de pacientes con enfermedad de Alzheimer & 57 \\
Humano & $\begin{array}{l}\text { Tratamiento de la anemia del neonato en la enfermedad } \\
\text { hemolítica perinatal }\end{array}$ & 58 \\
\hline
\end{tabular}


aguda. Dicho proceso implica el descenso en los niveles circulantes de EPO y la expresión de ciertas moléculas de adhesión aún no identificadas, sobre los eritrocitos jóvenes que le permiten al sistema retículo endotelial llevar a cabo su eliminación. Sin el fenómeno de la neocitólisis, la adaptación a la plétora sería lenta y tediosa (49).

La neocitólisis contradice el dogma tradicional que señala que no existen mecanismos fisiológicos que recorten la vida del eritrocito maduro, que la masa celular circulante eritrocitaria está controlada por la EPO únicamente a nivel de su producción y que la EPO actúa exclusivamente sobre los precursores eritroides tempranos (50). Este fenómeno refuerza el concepto fisiológico que establece que los factores de crecimiento no influyen solamente en la proliferación y maduración de una línea celular específica, sino que además determina la supervivencia de la progenie.

\section{Usos clínicos no eritropoyéticos de la rHuEPO}

Uno de los aspectos más interesantes de la biología celular de la rHuEPO se refiere a su actual y potencial utilidad en diversas áreas de la medicina. Además de los ya conocidos efectos benéficos de la citoquina en el manejo de la anemia crónica presente en muchas patologías, aparecen ahora nuevos y fascinantes descubrimientos de su papel en el pronóstico de distintos cuadros nosológicos que motivan el trabajo investigativo constante. En la tabla 2 se resumen algunos de los usos de la EPO.

En conclusión, las múltiples acciones biológicas de la rHuEPO, así como la gran diversidad de tejidos donde se expresa su receptor, hacen de ésta molécula una de las herramientas terapéuticas más útiles en el manejo de los pacientes que, no sólo padecen de anemia crónica, sino que además padecen de otras condiciones relacionadas en términos generales, con una reducción aguda o crónica, de la perfusión tisular. Lo anterior amplía el panorama de la rHuE$\mathrm{PO}$ como sensor y regulador de la oxigenación y el metabolismo celular.

\section{Referencias}

1. Bert P. La Pression Barometrique. Recherches de physiologie experimentale. Masson, Paris. 1878.
2. Carnot P, DeFlandre C. Sur l'activite Hemopoietique de Serum au Cours de la Regeneration du Sang. Les Comptes Rendus de l'Académie des Dciences. 1906;143:384-386.

3. Reissmann K R. Studies on the Mechanism of Erythropoietin Stimulation in Parabiotic Rats during Hypoxia. Blood. 1950;5:347-380.

4. Jacobson L O, Goldwasser E, Fried W, Plzak L. Role of the Kidney in Erythropoiesis. Nature. 1957;179:633.

5. Miyake T, Kung C K, Goldwasser E. Purification of Human Erythropoietin. The Journal of Biological Chemistry. 1977;252:5558-5564.

6. Lin F K, Suggs S, Lin C H, Browne J K, Smailing R, Egric $\mathrm{J}$ C. Cloning and Expression of the Human Erythropoietin Gene. Proceedings of the National Academy of Sciences. 1985;92:7850-7884.

7. Osterborg A. New Drythropoietic Proteins: Rationale and Clinical Data. Seminars in Oncology. 2004;31:12-18.

8. Sathyanarayana P, Dev A, Fang J, Houde E, Bogacheva O. EPO Receptor Circuits for Primary Erythroblast Survival. Blood. 2008;111(11):5390-9.

9. Jacobs K. Isolation and Characterization of Genomic and cDNA Clones of Human Erythropoietin. Nature. 1985;313:806.

10. Wu H, Liu X, Jaenisch R, Lodish HF. Generation of Committed Erythroid BFU-E and CFU-E Progenitors does not Required Erythropoietin or the Erythropoietin Receptor. Cell. 1995;83:59-67.

11. Sirén AL, Fasshauer T, Bartels C, Ehrenreich H. Therapeutic Potential of Erythropoietin and its Structural or Functional Variants in the Nervous System. Neurotherapeutics. 2009;6(1):108-27.

12. Masuda S, Okano M, Yamagishi K. A Novel Site of Erythropoietin Production. Oxygen-dependent Production in Cultured Rat Astrocytes. The Journal of Biological Chemistry. 1994;269:19488-93.

13. Siren A, Fratelli M, Brines M, Goemans C, Casagrande S, Lewczuk P. Erythropoietin Prevents Neural Apoptosis after Cerebral Ischemia and Metabolic Stress. Proceedings of the National Academy of Sciences. 2001;98:4044-49.

14. Leist M, Ghezzi P, Grasso G, Bianchi R, Villa P, Fratelli M. Derivates of Erythropoietin that are Tissue Protective but not Erythropoietic. Science. 2004;305:239-242.

15. Ribatti D, Vacca A, Roccaro A M, Crivellato E, Presta M. Erythropoietin as an Angiogenic Factor. European Journal of Clinical Investigation. 2003;33(10):891-896.

16. Sasaki R, Masuda S, Nagao M. Pleiotropic Functions and Tissue Specific Expression of Erythropoietin. News Physiology Sciences. 2001;16:110-113.

17. Weiss M. New Insights into Erythropoietin and Epoetin alfa: Mechanism of Action, Target Tissues, and Clinical Applications. The Oncologist. 2003;8(3):18-29.

18. Socolovsky M, Fallon A, Wang S, Brugnara C, Lodish H. Fetal Anemia and Apoptosis of Red Cell Progenitors in Stat5a-/5b-/- Mice: A Direct Role for Stata5 in Blc-XL Induction. Cell. 1999;98:181-191.

19. Weiss M J, Keller G, Orkin S H. Novel Insights into Erythroid Development Revealed Through in Vitro Differentiation of GATA-1-/- Embryonic Stem Cells. Genes and Development. 1994;8:1197.

20. Kuwana T, MacKey M, Perkins G, Ellisman M, Latterich M, Schneiter R. Bid, Bax and Lipids Cooperate to for Supramolecular Openings in the Outer Mitochondrial Membrane. Cell. 2002;111:331-342.

21. Motoyama N, Kimma T, Takahashi T, Watanabe T, Nakano T. Bcl-x Prevents Apoptotic Cell Death of Both Primitive and Definitive Erythrocytes at the End of Maduration. The Journal of Experimental Medicine. 1999;189:1691-98. 
22. Wagner K, Claudio E, Rucker E, Riedinger G, Broussard C, Schwartzberg P. Conditional Deletion of the Bcl-XL Gene from Erythroid Cells Results in Haemolytic Anemia and Profund Splenomegaly. Development. 2000;127:4949-4958.

23. Medhab K, Angery-Bouget Y, Minatchy M. Bcl-XL is Required for Heme Synthesis during the Chemical Induction of Erythroid Differentiation of Murine Erythroleukemia Cells Independently of its Anti-apoptotic Function. Blood. 2003;101:2575-83.

24. Chu X, Cheung J, Barber D, Birnbaumer L, Rothblum L, Conrad K. Erythropoietin Modulates Calcium Influx Through TRPC2. The Journal of Biological Chemistry. 2002;277:34375-82.

25. Rizzo J D, Seidenfeld J, Piper M, Aronson N, Lichtin A, Littlewood T J. Erythropoietin: A Paradigm for the Development of Practice Guidelines. Hematology, American Society of Hematology Education Program). 2001;10-30.

26. Glaspy J A. Erythropoietin in Cancer Patients. Annual Review of Medicine. 2009;60:181-92.

27. Littlewood T, Bajetta E, Nortier J, Vercammen E, Rapoport B. Effects of Epoetin alfa on Hematologic Parameters and Quality of Life in Cancer Patients Receiving Nonplatinium Chemotherapy: Results of a Randomized, Double-bind, Placebo-controlled Trial. Journal of Clinical Oncology. 2001;19:2865-74.

28. Itri L. The use of Epoetin alfa in Chemotherapy Patients: A Consistent Profile of Efficacy and Safety. Seminars in Oncology. 2002;29(8):81-87.

29. Piron M, Loo M, Gothot A, Tassin F, Fillet G, Beguin Y. Cessation of Intensive Treatment with Recombinant Human Erythropoiesis is Followed by Secondary Anemia. Blood. 2001;97:442-8

30. Polenakovik M, Sikole A. Is Erythropoietin a Survival Factor for Red Blood Cells? Journal of the American Society of Nephrology. 1996; 7:1178-1182.

31. Lang K, Duraton C, Poehlmann H, Myssina S, Bauer C, Lang F. Cation Channels Trigger Apoptotic Death of Erythrocytes. Cell Death and Differentiation. 2003;10:249-56.

32. Myssina S, Huber S, Birka C, Lang P, Lang K, Friedrich B. Inhibition of Erythrocyte Cation Channels by Erythropoietin. Journal of the American Society of Nephrology. 2003; 14:2750-57

33. Lang P, Kaiser S, Myssina S, Wieder T, Lang F and Huber S. Role of $\mathrm{Ca}+2$ Activated $\mathrm{K}+$ Channels in Human Erythrocyte Apoptosis. American Journal of Physiology. 2003;285:155360.

34. Bratosin D, Estaquier J, Ameisen J C, Montreuil J. Molecular and Cellular Mechanism of Erythrocyte Programmed Cell Death: Impact on Blood Transfusion. Vox Sanguinis. 2002;83(1):307-10.

35. Bratosin D, Estaquier J, Petit F, Arnoult D, Montreuil J, Ameisen J. Programmed Cell Death in Mature Erythrocytes: A Model for Investigating Death Effector Pathways Operating in Absence of Mitochondria. Cell Death and Differentiation. 2001;8:1143-56.

36. Berg C, Engels I, Rothbard A, Lauber K, Renz A, Schlosser J. Human Mature Red Blood Cells Express Caspase-3 and Caspase-8, But are Devoid of Mitochondiral Regulators of Apoptosis. Cell Death and Differentiation. 2001;8:1197-206.

37. Micheti M, Salamino F, Minafra R, Melloni E and Pontremoli S. Calcium-Binding Properties of Human Erythrocyte Calpain. Biochemical Journal. 1997;325:721-26.

38. Lockshin R, Zakeri Z. Caspase-independent Cell Death? Oncogene. 2004;23:2766-73.
39. Daugas E, Candé C, Kroemer G. Erythrocytes: Death of a Mummy. Cell Death and Differentiation. 2001;8:1131-33.

40. Banerjee T, Kuypers F. Reactive Oxygen Species and Phosphatidilserine Externalization in Murine Sickle Red Cells. British Journal of Haematology. 2004;124:391-402.

41. Mandal D, Moitra P, Saha S, Basu J. Caspase 3 Regulates Phosphatidylserine Externalization and Phagocytosis of Oxidatively Stressed Erythrocytes. FEBS Letters. 2002;513:184188.

42. Daleke D and Lyles J. Identification and Purification of Aminophospholipid Flippases. Biochimica et Biophysica Acta. 2000;1486:108-27.

43. Mandal D, Baudin-Creuza V, Bhattacharyya A, Pathak S, Delaunay J, Kundu M. Caspase 3-mediated Proteolysis of the Nterminal Cytoplasmic Domain of the Human Erythroid Anion Exchanger 1 (Band 3). The Journal of Biological Chemistry. 2003;278:52551-558.

44. Alfrey C P, Rice L, Udden M M, Driscoll T B. Neocytolysis: Physiological Down-regulation of Red-cell Mass. Lancet. 1997;349:1389-90.

45. Alfrey C P, Udden M M, Leach-Huntoon C L, Driscoll T, Pickett M H. Control of Red Blood Cell Mass in Spaceflight. Journal of Applied Physiology. 1996;81:98-104.

46. Alfrey C P, Udden M M, Huntoon C L, Driscoll T. Destruction of Newly Released Red Blood Cells in Space Flight. Medicine and Science in Sports and Exercise. 1996:28:42-44

47. Lankhorst C E, Wish J B. Anemia in Renal Disease: Diagnosis and Management. Blood Reviews. 2010;24(1):39-47.

48. Trial J, Rice L, Alfrey C P. Erythropoietin Withdrawal Alters In teractions Between young Red Blood Cells, Splenic Endothelial Cells and Macrophages: and in Vitro Model of Neocytolysis. Journal of Investigative Medicine. 2001;49:335-45.

49. Rice L, Ruiz W, Driscoll T, Whitley C, Tapia R, Hachey D. Neocytolysis on Descent from Altitude: A Newly Recognized Mechanism for the Control of the Red Cell Mass. Annals of Internal Medicine. 2001;134:652-56.

50. Cheung J Y, Zhang X Q, Bokvist K, Tillotson D L, Miller B A Modulation of Calcium Channels in Human Erythroblasts by Erythropoietin. Blood. 1997;89:92-100.

51. Wang Q, Pfister F, Dorn-Beineke A. Low-dose Erythropoietin Inhibits Oxidative Stress and Early Vascular Changes in the Experimental Diabetic Retina. Diabetologia. 2010;53(6):1227-38.

52. Digicaylioglu M. Erythropoietin in Stroke: Quo Vadis. Expert Opinion on Biological Therapy. 2010;10(6):937-49.

53. Turk E, Karaca I, Karkiner A. Effect of Intraperitoneal Erythropoietin on the Degree of Mucosal Damage of Left Colon Flaps in Rats. Pediatric Surgery International. 2010;26(6):633-8.

54. Wüstenberg T, Begemann M, Bartels C. Recombinant Human Erythropoietin Delays Loss of Gray Matter in Chronic Schizophrenia. Molecular Psychiatry. 2010, May 18.

55. Ueda K, Takano H, Niitsuma Y. Sonic Hedgehog is a Critical Mediator of Erythropoietin-induced Cardiac Protection in Mice. The Journal of Clinical Investigation. 2010, May 17.

56. Neubauer AP, Voss W, Wachtendorf M. Erythropoietin Improves Neurodevelopmental Outcome of Extremely Preterm Infants. Annals of Neurology. 2010;67(5):657-66.

57. Modabbernia A, Ashrafi M, Modabbernia M J. Let”s Try Erythropoietin in Alzheimer's Disease. Medical Hypotheses. 2010, Apr 10.

58. Zuppa A A, Alighieri G, Calabrese V. Recombinant Human Erythropoietin in the Prevention of Late Anemia in Intrauterine Transfused Neonates with Rh-Isoimmunization. Journal of Pediatric Hematology/Oncology. 2010;32(3):95-101. 